\title{
qDNase assay: A quantitative method for real-time assessment of DNase activity on coated surfaces
}

\author{
Marie Van der Gucht ${ }^{\mathrm{a}}$, Merve Kübra Aktan ${ }^{\mathrm{b}}$, Hanne Hendrix ${ }^{\mathrm{a}}$, Greetje Vande Velde ${ }^{\mathrm{c}}$, \\ Jan Paeshuyse ${ }^{\mathrm{d}}$, Annabel Braem ${ }^{\mathrm{b}}$, Rob Lavigne ${ }^{\mathrm{a}, *}$ \\ ${ }^{a}$ KU Leuven, Department of Biosystems, Laboratory of Gene Technology, Kasteelpark Arenberg 21 - box 2462, B-3001, Leuven, Belgium \\ ${ }^{\mathrm{b}}$ KU Leuven, Department of Materials Engineering (MTM), Biomaterials and Tissue Engineering Research Group, Kasteelpark Arenberg 44 - box 2450, B- \\ 3001, Leuven, Belgium \\ ${ }^{c}$ KU Leuven, Department of Imaging \& Pathology, Biomedical MRI / MoSAIC, Herestraat 49, building O\&N1 - box 505, B-3000, Leuven, Belgium \\ ${ }^{\mathrm{d}}$ KU Leuven, Department of Biosystems, Laboratory of Host Pathogen Interaction in Livestock, Kasteelpark Arenberg 30 - box 2472, B-3001, Leuven, Belgium
}

\section{A R T I C L E I N F O}

\section{Article history:}

Received 14 October 2020

Accepted 17 October 2020

Available online xxx

\section{Keywords:}

Anti-biofilm

Coatings

Quantitative enzyme assay

DNase

Fluorescence

\begin{abstract}
A B S T R A C T
DNase coatings show great potential to prevent biofilm formation in various applications of the medical implant, food and marine industry. However, straightforward and quantitative methods to characterize the enzymatic activity of these coatings are currently not available. We here introduce the qDNase assay, a quantitative, real-time method to characterize the activity of DNase coatings. The assay combines (1) the use of an oligonucleotide probe, which fluoresces upon cleavage by coated DNases, and (2) the continuous read-out of the fluorescent signal within a microplate fluorometer format. The combination of these two properties results in a real-time fluorescent signal that is used to directly quantify the activity of DNase coatings. As a proof of concept, bovine DNase I coatings were immobilized on titanium by means of chemical grafting and their activity was estimated at $3.87 \times 10^{-4} \mathrm{U}$. To our knowledge, the qDNase assay provides the first approach to report the activity of a DNase coating in absolute DNase activity units. This assay will not only serve to compare existing DNase coating methods more accurately, but will also enable the rational design of new DNase coating methods in the future.
\end{abstract}

(c) 2020 Elsevier Inc. All rights reserved.

\section{Introduction}

Enzyme-based coatings have high potential for the development of next generation biofilm prevention strategies. Preventing microbial biofilms is of critical importance for a range of industries, including the medical implant, food and marine industry [1-3]. Within the context of infectious diseases and the emergence of antibiotic resistance, several types of enzymes have been identified to effectively target the bacterial biofilm mode-of-growth, either directly (bactericidal) or indirectly (targeting key components within the biofilm matrix) [4-6]. A combination of their low propensity to resistance development, limited toxicity and low environmental impact has attracted the interest for these anti-biofilm enzymes. Moreover, when applied as a local coating on the device of interest, these enzymes will be available at the site and time of biofilm establishment.

\footnotetext{
* Corresponding author.

E-mail address: rob.lavigne@kuleuven.be (R. Lavigne).
}

One type of effective anti-biofilm enzymes are deoxyribonucleases (DNases). DNases degrade extracellular DNA, a component of the biofilm matrix that contributes to biofilm attachment, structural stability and increased antimicrobial resistance [7]. Accordingly, DNase treatments can effectively prevent, disrupt and sensitize biofilms of various species, including Pseudomonas aeruginosa and Staphylococcus aureus, which are two of the most prevalent species in implant-associated infections [8-10]. Recently, a number of anti-biofilm DNase coatings have been developed on a range of polymeric substrates, such as polymethylmethacrylate (PMMA), poly(styrene- $b$-isobutylene- $b$-styrene) (SIBS) and polydimethylsiloxane (PDMS), as well as metals, such as titanium. Coating strategies included immobilization through chemical grafting for permanent DNase activity at the surface or incorporation in a biodegradable poly-(lactic-co-glycolic)-acid (PLGA) overcoat allowing a gradual DNase release from the surface [11-15].

Despite this clear interest in DNase coatings as anti-biofilm strategy, a straightforward and quantitative assay to measure the enzymatic activity of DNase-coated surfaces is currently unavailable. 
In traditional assays to detect the activity of DNase coatings, a DNAcontaining solution is brought into contact with the coated surface. At distinct time points, samples are taken and analyzed by agarose gel electrophoresis to observe the degradation of the substrate DNA $[11,15]$. Although this assay can provide some semi-quantitative information on the reaction progress, manual sampling limits the number of time points, causing valuable information to be lost. In addition, it reduces the assay reproducibility and limits the throughput of coatings that can be assessed in parallel.

To address these limitations, we here introduce a straightforward and quantitative assay to measure the activity of DNasecoated surfaces in real-time. This assay allows objective evaluation of existing DNase coatings and will enable rational optimization of new DNase coating strategies.

\section{Materials and methods}

\subsection{Preparation of DNase coatings on titanium}

DNases were immobilized on commercially pure titanium discs (grade $2, \emptyset=5 \mathrm{~mm}$, thickness $=2 \mathrm{~mm}$; Salomon's Metalen, the Netherlands) by means of chemical grafting. To obtain a reproducible surface finish on the substrate materials, discs were grinded using an automatic polishing machine (Struers, Denmark), equipped with resin bonded diamond grinding discs (MD-Mezzo 220 and MD Largo; Struers). This was followed by polishing with an Oxide Polishing Suspension (OPS) of colloidal silica (Microdiamant, Germany) and hydrogen peroxide (Chem-Lab, Belgium) mixture (30\% $\mathrm{H}_{2} \mathrm{O}_{2}, 70 \%$ OPS) on a polishing cloth (Galaxy Polishing Cloth Omega; Advanced Metallography, Germany). Afterwards, discs were ultrasonically cleaned (Branson 2510, USA) in ultrapure water (Milli-Q; Merck Millipore, USA) and technical ethanol (Disolol; Chem-Lab) for 10 min each. To covalently couple DNase I molecules to the titanium surface, polished titanium (Pol-Ti) surfaces were first functionalized using dopamine (DA, 99\%; Alfa Aesar, USA). To this end, discs were immersed in a dopamine solution $(1 \mathrm{mg} / \mathrm{ml}$ in $10 \mathrm{mM}$ Tris- $\mathrm{HCl}, \mathrm{pH} 8.5$ ) for $24 \mathrm{~h}$ in the dark. Dopaminefunctionalized titanium (DA-Ti) discs were rinsed, dried and then stored at $4{ }^{\circ} \mathrm{C}$ until use. Finally, DA-Ti discs were immersed in $5 \mathrm{ml}$ of a $35 \mathrm{U} / \mathrm{ml}$ bovine DNase I (2814 U/mg, D5025; Sigma-Aldrich, USA) solution in phosphate buffer $\left(4.6 \mathrm{mM} \mathrm{K}_{2} \mathrm{HPO}_{4}, 5.4 \mathrm{mM}\right.$ $\mathrm{KH}_{2} \mathrm{PO}_{4}, 150 \mathrm{mM} \mathrm{NaCl}, 10 \mathrm{mM} \mathrm{MgCl}$, $\mathrm{pH}$ 6.8) for 6 h at room temperature. The DNase-coated titanium (DNase-Ti) discs were rinsed in Milli-Q to remove excess DNase, dried and immediately used for activity assessment.

\subsection{Activity assessment of DNase-Ti}

Analysis of DNase-Ti using the qDNase assay. Discs were carefully placed in a separate well of a black polystyrene 96-well plate (Nunc ${ }^{\mathrm{TM}}$, Thermo Scientific, USA). A $100 \mu \mathrm{l}$ volume of the reaction mixture $\left(200 \mathrm{nM}\right.$ DNaseAlert ${ }^{\mathrm{TM}}$ substrate in $1 \mathrm{x}$ DNaseAlert ${ }^{\mathrm{TM}}$ buffer; IDT, USA) was added to each well and the fluorescent signal was measured with the CLARIOStar plus multimode microplate reader (BMG LABTECH, Germany) (Table 1). Four replicate DNase-Ti discs were analyzed in parallel using Pol-Ti as a negative control. The activity of DNase-Ti was converted to equivalent activity units of free DNase I using a calibration curve. For this, five linear dilutions of DNase I were prepared in phosphate buffer and $10 \mu \mathrm{l}$ was added to a reaction mixture (200 nM DNaseAlert ${ }^{\mathrm{TM}}$ substrate in $1 \mathrm{x}$ DNaseAlert'TM buffer) in a total volume of $100 \mu \mathrm{l}$. The fluorescent signal of each DNase I standard was measured using the same settings as described above in the presence of Pol-Ti. Phosphate buffer served as a negative control.

Analysis of DNase-Ti using the traditional assay. A $40 \mu \mathrm{l}$ solution of $90 \mathrm{ng} / \mu \mathrm{l}$ lambda DNA (Thermo Scientific) in Tris buffer ( $10 \mathrm{mM}$ Tris$\mathrm{HCl}, 2.5 \mathrm{mM} \mathrm{MgCl}_{2}, 0.1 \mathrm{mM} \mathrm{CaCl}_{2}, \mathrm{pH} 7.5$ ) was placed on each disc and incubated at $37^{\circ} \mathrm{C}$. At $0,15,30,60$ and $90 \mathrm{~min}, 5 \mu \mathrm{l}$ aliquots were analyzed by agarose gel electrophoresis using a $1 \%$ agarose gel. Four replicate DNase-Ti discs were analyzed in parallel using Pol-Ti as a negative control.

\subsection{Data analysis}

Data analysis was performed using Microsoft Excel 2016. To quantify the activity from a negative control-corrected fluorescence curve, the initial reaction rate was calculated as the slope of the linear region. The most reliable linear region was selected by using the dataset with maximized $\mathrm{R}^{2}$-value [16]. The calibration curve was obtained by plotting the initial reaction rates of the DNase I standards against their corresponding activity in units. A regression analysis was performed to estimate the calibration function, which allowed to predict the DNase-Ti activity in absolute DNase I units. Standard deviation of predicted activity was calculated using the following equation (Eq. (1)) [17]:

$s_{x_{0}}=\frac{s(r)}{m} \sqrt{\frac{1}{N}+\frac{1}{n}+\frac{\left(\bar{y}_{0}-\bar{y}\right)^{2}}{m^{2} \sum_{i=1}^{n}\left(x_{i}-\bar{x}\right)^{2}}}$

where $s(r)$ is the standard error of the fitted calibration function, $m$ is the slope of the fitted calibration function, $N$ is the number of

Table 1

Settings of the microplate fluorometer.

\begin{tabular}{|c|c|}
\hline Kinetic settings & \\
\hline No. of cycles & 480 \\
\hline Cycle time & $15 \mathrm{~s}$ \\
\hline No. of flashes per well and cycle & 20 \\
\hline Temperature & $37^{\circ} \mathrm{C}$ \\
\hline \multicolumn{2}{|l|}{ Optic settings } \\
\hline Excitation (wavelength - bandwidth) & $520 \mathrm{~nm}-20 \mathrm{~nm}$ \\
\hline Dichroic filter & $542.5 \mathrm{~nm}$ \\
\hline Emission (wavelength - bandwidth) & $570 \mathrm{~nm}-30 \mathrm{~nm}$ \\
\hline Gain & Enhanced Dynamic Range \\
\hline Focal Height & $7.0 \mathrm{~mm}$ \\
\hline Reading mode & Top \\
\hline \multicolumn{2}{|l|}{ Shaking settings } \\
\hline Timing & Before each cycle \\
\hline Movement & Double orbital \\
\hline Frequency & $300 \mathrm{rpm}$ \\
\hline Time & $5 \mathrm{~s}$ \\
\hline
\end{tabular}


measured DNase-Ti replicates, $n$ is the number of paired calibration points, $\bar{y}_{0}$ is the average initial reaction rate of the $N$ DNase-Ti replicates, $\bar{y}$ is the average initial reaction rate of the $n$ DNase I standards, $x_{i}$ is the activity of a DNase I standard in absolute units and $\bar{x}$ is the average activity of the $n$ DNase I standards. Data visualizations were made with GraphPad Prism 8.4.3.

\section{Results}

To evaluate the qDNase assay in a proof-of-concept set-up, the activity of DNase-Ti discs was assessed using both the traditional assay and the qDNase assay. Pol-Ti discs were used as a negative control in both assays. In the traditional assay, the reaction progress was followed at distinct time points by visualizing the DNA pattern that resulted from degradation of the DNA solution by DNase-Ti (Fig. 1, Supplementary Fig. S1). Although this information would allow to evaluate different coatings as 'more active' or 'less active' to a certain extent by e.g. densitometric analysis, this assay fails to make a quantification of the coating activity and does not provide accurate real-time insights.

In the qDNase assay, the reaction progress was tracked in realtime by measuring the increase in fluorescent signal, resulting

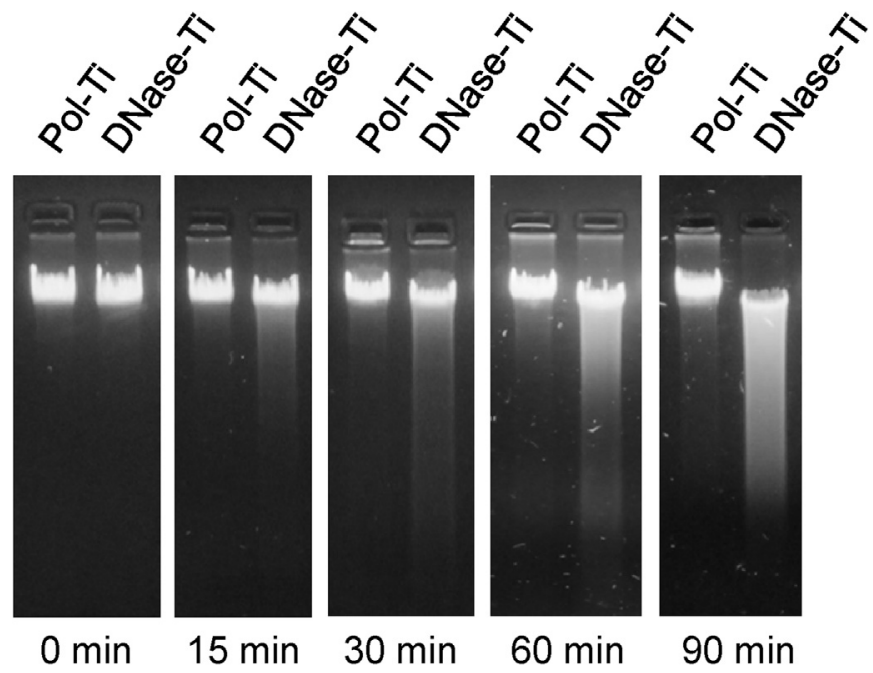

Fig. 1. Analysis of DNase-Ti activity using the traditional assay. Agarose gels show the degradation of $3.6 \mu \mathrm{g}$ substrate DNA after $0,15,30,60$ and $90 \mathrm{~min}$ by DNase-Ti. Pol-Ti was used as a negative control (See Fig. S1 for additional replicates). from the fluorescent oligonucleotide probe degradation by DNaseTi (Fig. 2A, Supplementary Fig. S2). To quantify the DNase-Ti activity, the initial reaction rate was calculated as the slope of the linear region of the resulting dataset (Supplementary Excel Sheet 1). Applying this to the four replicates, an initial reaction rate of $29.4 \pm 4.7 \mathrm{RFU} / \mathrm{s}$ was obtained. To calculate the absolute activity of the coating in equivalent units of free DNase, a calibration curve was required. This curve was set up by measuring the activity of a range of DNase I standards, using identical reaction conditions and microplate reader settings. Next, the initial reaction rates obtained were plotted against the corresponding DNase I activity to establish a calibration curve (Fig. 2B, Supplementary Excel Sheet 2). From the identified function, the absolute activity of the DNase-Ti discs could be estimated at $3.87 \times 10^{-4} \pm 0.31 \times 10^{-4} \mathrm{U}$ (Fig. 2B).

\section{Discussion}

Based on this proof of concept, it is clear that the qDNase assay is a straightforward method to obtain new insights in DNase coatings. From a fundamental perspective, the assay enables the kinetic behavior analysis of coated DNase. Indeed, although coating strategies can substantially change enzyme kinetics, the influence of different coating strategies on DNase kinetics remains largely unexplored. From an application perspective, the assay allows objective comparison between different DNase coatings [11-15]. In addition, it can guide the rational design of novel coating strategies by optimizing different process parameters (e.g. coating technique, enzyme concentration, process duration, etc.). Indeed, by estimating the absolute activity of DNase-Ti, we indicated that the activity yield of the used immobilization technique is only $0.00022 \%$, leaving plenty of room for optimization of DNase coating strategies. Moreover, the qDNase assay can serve to evaluate several application-oriented characteristics of DNase coatings, like activity in the presence of different additives or optimal storage conditions.

With this assay, we introduce a new application of the DNaseAlert ${ }^{\mathrm{TM}}$ probe. Originally, this product is sold as a rapid DNase detection agent. In addition, its application to measure kinetics of soluble DNases has been previously reported $[18,19]$. To our knowledge, this is the first report that uses this probe to characterize coated DNases. This choice of probe offers several advantages. First, a fluorescent signal is compatible with the presence of non-transparent coating substrates, like the commonly used stainless steel and titanium. Second, the probe bypasses the use of traditional nucleic acid dyes for DNA detection, which greatly simplifies optimization of the assay and interpretation of the
A

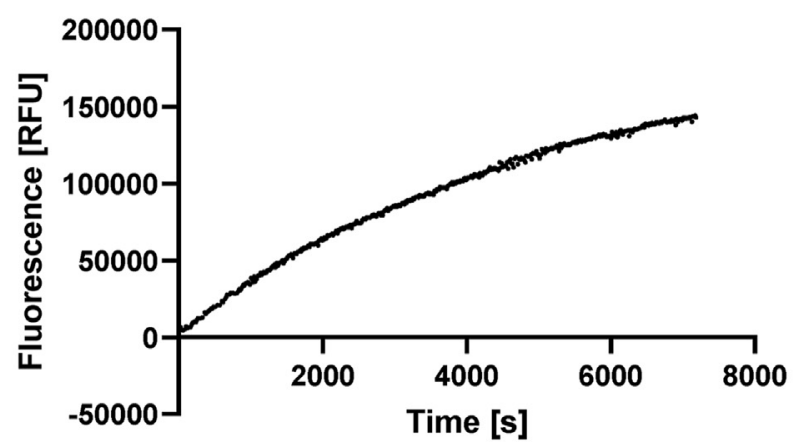

B

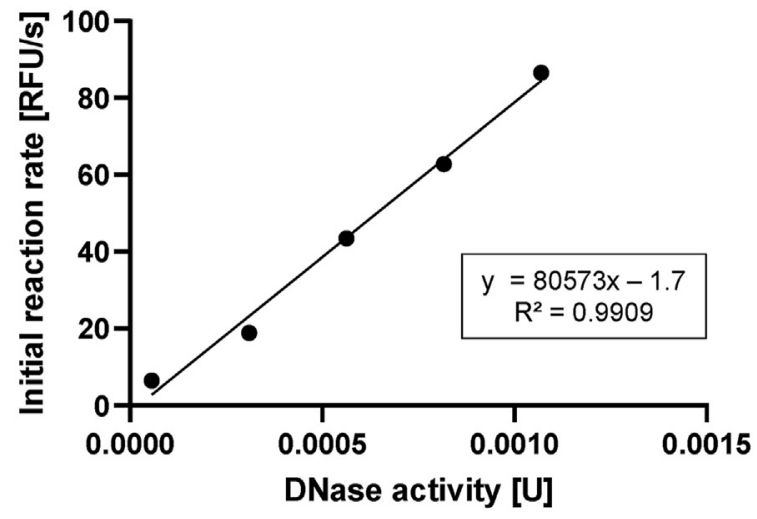

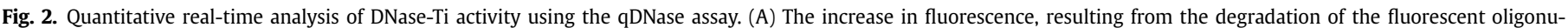

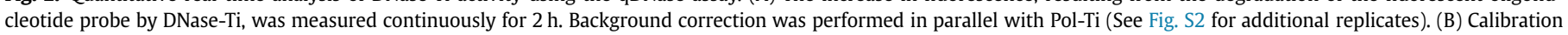
curve to convert initial reaction rate to absolute DNase activity in units, based on a linear dilution series of known DNase activities. 
results. Third, traditional nucleic acid dyes are generally mutagenic, requiring additional biological safety requirements and limiting the reusability of coatings and coated substrates. Similar DNase detection agents, such as DNaseAlert ${ }^{\mathrm{TM}} \mathrm{QC}$ system (Ambion), DNase I assay kit (Abcam) and DNase Detection Kit (Jena Biosciences), are available and are expected to be compatible with the qDNase assay. In addition, it can be envisioned to expand this assay to different enzymes, as fluorescent probes have been designed to detect a wide range of enzymes (e.g. proteases, glucosidases, etc.) [20].

The fluorescent signal is measured here in a microplate reader format. In contrast to the traditional assays, this set-up circumvents the need to take samples at individual time points, and provides real-time information. In this way, it reduces effort and improves reproducibility. Moreover, since multiple reactions can be measured in parallel, the throughput of the assay increases substantially. In the described proof of concept, we used titanium discs that precisely match the dimensions of a 96-well plate. However, different set-ups for larger coated substrates can be envisioned by using microplates with larger wells. Alternatively, when a microplate fluorometer is not available, the assay can also be read using any other device that measures fluorescence. Nevertheless, we believe that the set-up reported here requires the least substrate and obtains measurements under the most controlled conditions with a maximal throughput.

In conclusion, by combining the use of a fluorescent oligonucleotide probe with a continuous signal read-out, we introduced the qDNase assay to quantify the activity of DNase coatings. This assay will not only serve to compare existing DNase coating methods more accurately, but will also enable the rational design of new DNase coating methods in the future.

\section{Declaration of competing interest}

The authors declare that they have no known competing financial interests or personal relationships that could have appeared to influence the work reported in this paper.

\section{Acknowledgements}

This work was supported by the Research Foundation - Flanders (FWO) [1S43118N]; and by KU Leuven [C32/18/010, STG/17/ 024].

\section{Appendix A. Supplementary data}

Supplementary data to this article can be found online at https://doi.org/10.1016/j.bbrc.2020.10.050.

\section{References}

[1] S.V. Pavlukhina, J.B. Kaplan, L. Xu, W. Chang, X. Yu, S. Madhyastha,
N. Yakandawala, A. Mentbayeva, B. Khan, S.A. Sukhishvili, Noneluting enzymatic antibiofilm coatings, ACS Appl. Mater. Interfaces 4 (2012) 4708-4716, https://doi.org/10.1021/am3010847.

[2] G. Yeroslavsky, O. Girshevitz, J. Foster-frey, D.M. Donovan, S. Rahimipour, Antibacterial and antibiofilm surfaces through polydopamine-assisted immobilization of lysostaphin as an antibacterial enzyme, Langmuir 31 (2015) 1064-1073, https://doi.org/10.1021/la503911m.

[3] E. Aykin, B. Omuzbuken, A. Kacar, Microfouling bacteria and the use of enzymes in eco-friendly antifouling technology, J. Coat. Technol. Res. 16 (2019) 847-856, https://doi.org/10.1007/s11998-018-00161-7.

[4] J.B. Kaplan, Therapeutic potential of biofilm-dispersing enzymes, Int. J. Artif. Organs 32 (2009) 545-554, https://doi.org/10.1177/039139880903200903.

[5] B. Thallinger, E.N. Prasetyo, G.S. Nyanhongo, G.M. Guebitz, Antimicrobial enzymes: an emerging strategy to fight microbes and microbial biofilms, Biotechnol. J. 8 (2013) 97-109, https://doi.org/10.1002/biot.201200313.

[6] S. Nahar, M.F.R. Mizan, A.J. Ha, S.-D. Ha, Advances and future prospects of enzyme-based biofilm prevention approaches in the food industry, Compr. Rev. Food Sci. Food Saf. 17 (2018) 1484-1502, https://doi.org/10.1111/15414337.12382.

[7] M. Okshevsky, R.L. Meyer, The role of extracellular DNA in the establishment, maintenance and perpetuation of bacterial biofilms, Crit. Rev. Microbiol. 41 (2015) 341-352, https://doi.org/10.3109/1040841X.2013.841639.

[8] C.R. Arciola, Y.H. An, D. Campoccia, M.E. Donati, L. Montanaro, Etiology of implant orthopedic infections: a survey on 1027 clinical isolates, Int. J. Artif. Organs 28 (2005) 1091-1100, https://doi.org/10.1177/039139880502801106.

[9] P. Chaignon, I. Sadovskaya, C. Ragunah, N. Ramasubbu, J.B. Kaplan, S. Jabbouri, Susceptibility of staphylococcal biofilms to enzymatic treatments depends on their chemical composition, Appl. Microbiol. Biotechnol. 75 (2007) 125-132, https://doi.org/10.1007/s00253-006-0790-y.

[10] G.V. Tetz, N.K. Artemenko, V.V. Tetz, Effect of DNase and antibiotics on biofilm characteristics, Antimicrob. Agents Chemother. 53 (2009) 1204-1209, https:// doi.org/10.1128/AAC.00471-08.

[11] J.J.T.M. Swartjes, T. Das, S. Sharifi, G. Subbiahdoss, P.K. Sharma, B.P. Krom, H.J. Busscher, H.C. van der Mei, A functional DNase I coating to prevent adhesion of bacteria and the formation of biofilm, Adv. Funct. Mater. 23 (2013) 2843-2849, https://doi.org/10.1002/adfm.201202927.

[12] S. Yuan, J. Zhao, S. Luan, S. Yan, W. Zheng, J. Yin, Nuclease-functionalized Poly(Styrene-b-isobutylene-b-styrene) surface with anti-infection and tissue integration bifunctions, Appl. Mater. Interfaces. 6 (2014) 18078-18086, https://doi.org/10.1021/am504955g.

[13] J.J.T.M. Swartjes, Innovative Coatings for Anti-bacterial Surfaces, University of Groningen, 2015.

[14] D. Alves, A. Magalhães, D. Grzywacz, D. Neubauer, W. Kamysz, M.O. Pereira, Co-immobilization of Palm and DNase I for the development of an effective anti-infective coating for catheter surfaces, Acta Biomater. 44 (2016) 313-322, https://doi.org/10.1016/j.actbio.2016.08.010.

[15] J. Ye, C. Shao, X. Zhang, X. Guo, P. Gao, Y. Cen, S. Ma, Y. Liu, Effects of DNase I coating of titanium on bacteria adhesion and biofilm formation, Mater. Sci. Eng. C 78 (2017) 738-747, https://doi.org/10.1016/j.msec.2017.04.078.

[16] Y. Briers, R. Lavigne, G. Volckaert, K. Hertveldt, A standardized approach for accurate quantification of murein hydrolase activity in high-throughput assays, J. Biochem. Biophys. Methods 70 (2007) 531-533, https://doi.org/ 10.1016/j.jbbm.2006.10.009.

[17] L. Prichard, V. Barwick, Preparation of Calibration Curves A Guide to Best Practice, 2003. https://doi.org/10.13140/RG.2.2.36338.76488.

[18] B. Altermark, L. Niiranen, N.P. Willassen, A.O. Smalås, E. Moe, Comparative studies of endonuclease I from cold-adapted Vibrio salmonicida and mesophilic Vibrio cholerae, FEBS J. 274 (2007) 252-263, https://doi.org/10.1111/ j.1742-4658.2006.05580.x.

[19] G.J. Knott, B.W. Thornton, M.J. Lobba, J.-J. Liu, B. Al-Shayeb, K.E. Watters, J.A. Doudna, Broad-spectrum enzymatic inhibition of CRISPR-Cas12a, Nat. Struct. Mol. Biol. 26 (2019) 315-321, https://doi.org/10.1038/s41594-0190208-z.

[20] C.R. Drake, D.C. Miller, E.F. Jones, Activatable optical probes for the detection of enzymes, Curr. Org. Synth. 8 (2011) 498-520, https://doi.org/10.2174/ 157017911796117232. 